\title{
27 Rediscovering Ancient Pathways for Regenerative Agriculture
}

\author{
Charles Massy \\ Australian National University
}

\section{CONTENTS}

Subtle Energy as the Next Big 'Freebie' in Agriculture ........................................................... 305

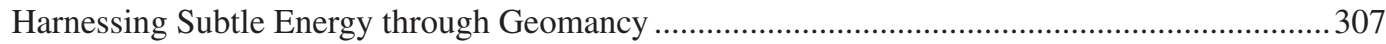

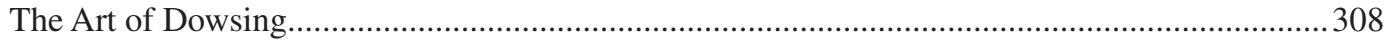

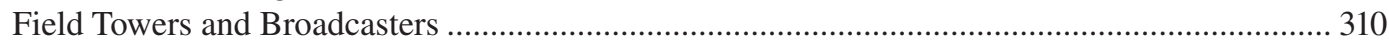

Indigenous Totems and Nature Spirits ............................................................................... 311

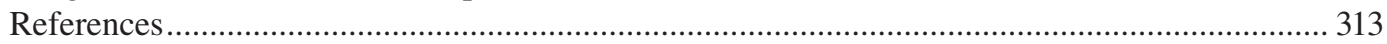

...water from plants, fire, clouds, rain, sun, moon, stars, stories and sites, songs, paintings, dancing... looking after country involves all of these things together - you can't have one without the other. Maintaining language and culture is a tool for relating to country and looking after everything that is on it.

Veronica Dobson, Arrernte Elder of Northern Australia, defining indigenous knowledge.

NAILSMA (2006: 3)

\section{SUBTLE ENERGY AS THE NEXT BIG 'FREEBIE' IN AGRICULTURE}

It is an early winter's day, 2013, in the inland city of Dubbo in Central West NSW. I am 1 of 20 or so farmers walking around a city park with two bent wire rods in my hands. They sit like giant revolvers, held out in front of us and pointing forward. We are learning to divine (or dowse), first for underground water streams and later for cosmic energy flows in the landscape. To my surprise, I find I can do this after only a brief lesson. I know because my two wires suddenly and violently cross onto my chest as I pass across either the stream or energy flow. The accurate locations of both water and energy streams are confirmed by others in the group, and particularly by our teacher, Dr. Patrick MacManaway. What I find even more remarkable is that I can dowse for a water stream, and not the energy stream, simply by focussing my thought-patterns - or my mental 'intent'. Though I had read about such mental power, for me this is the first confirmation. It had a deep impact.

What made me undertake the 7-hour drive to Dubbo for 3 days of workshops on 'subtle energies' is the increasing number of regenerative farmers I have met who have begun working with these energies. They are leading, practical, professional and profitable farmers and have come to this practice from different directions. Despite my initial scepticism, my increasing encounters with this issue meant that, in all integrity, I could no longer ignore it.

Patrick MacManaway is a Scot who gained a medical degree at the prestigious faculty of the University of Edinburgh. In 1994, he moved full time into working in the field of 'geomancy' and as a subtle energy expert, whereby he concentrates on enhancing the positive influences of subtle 
energy in our landscapes, infrastructure and animals - and specifically in regenerative agriculture. Today, he is internationally recognised and respected in his field.

MacManaway calls himself a holistic therapist. He helps farming landscapes and soils perform better, relieves 'geopathic' stress in landscapes (i.e. negative energy fields or flows) and is specifically skilled in using earth acupuncture to do so. His father, also a medically trained doctor, discovered he had a gift of healing when he was stranded with a battalion of soldiers and no medical supplies on the beach of Dunkirk in World War II. While they were being strafed by Messerschmitt, and as casualties mounted, his father's only tools were the physical laying-on of hands and providing kind words to his troops. And it worked, often in seemingly miraculous fashion. Patrick discovered he also had the 'gift', and so he switched to using the special sensitivities he had been endowed with to heal landscapes, people and animals via this different pathway.

Patrick MacManaway was first brought to Australia in 2010 by Terry McCosker and his Resource Consulting Services. McCosker had already introduced Australian farmers to the concept of subtle energies when he brought out the American expert Dr. Phil Wheeler to run workshops on dowsing in 2001. As more regenerative farmers experienced positive results from this programme, McCosker next invited MacManaway to broaden the implications of the positive use of subtle energies in farming and human health. Says McCosker, 'Sunlight and rainfall are natural assets which are seen as "freebies" in your production system that you can manage profit from. With the right knowledge and techniques, subtle energy is another natural asset that you can benefit from'. This leads McCosker to conclude that 'Subtle energy is the next big "freebie" in agriculture'.

From an exploration of the origins of biodynamics, it is clear that certain elements of Rudolf Steiner's work came from medieval European peasants. Such farmers could detect and work with ancient earth and cosmic energies and were connected to nature spirits, or what is called 'animism' - a trope for beliefs that the natural world is 'inspirited' - that is, inhabited by nature spirits, that a sacred reality exists and is different from everyday profane realities, and is manifested at special times and places, usually through natural entities and places (Taylor, 2005: xiii.). Yet it is the 'mechanical' mind that reigns supreme today. Thus, the world is now seen as a machine, deemed fully comprehensible by Western humanistic, rationalistic thought, and is regarded as without value or sensibility. This in turn renders it totally available for human control, domination and exploitation for profit. Here resides the great divorce, for we are no longer bonded to Mother Earth and have therefore lost some of our organic senses. The psychological consequence of this break of the human-Mother Earth bond - a fatal divorce - is what I believe has precipitated us into the Anthropocene era.

Anthropologist-philosopher Mircea Eliade says that 'the completely profane world, the wholly desacralised cosmos, is a recent discovery in the history of the human spirit' (Eliade, 1961: 13). I believe he is right. This makes it hard for those of our generation imbued with a post-Enlightenment, reductionist, mechanistic-minded, modern humanism - and increasingly moored in a 'rational' and profane or desacralised world - to comprehend, let alone identify, with those of other times and other minds who were - and still are - immersed in a sacred world. ${ }^{2}$ Such an 'organic' mind varied from culture to culture over time, but generally, in most eras, things such as place, space and time could assume sacred significance, as did natural, organic, geological and other elements. Even basic physiological acts such as eating, sex and so on were never just simply 'physiological', as Eliade says, they were or could become 'a sacrament... a communion with the sacred' (Eliade, 1961: 14).

As a student of this ancient organic mind, Mircea Eliade captured the almost intangible elements of the pre-mechanistic mind. The existential situation of people of such a mindset, says Eliade, is where 'life has an additional dimension; it is not merely human, it is at the same time cosmic, since

\footnotetext{
${ }^{1}$ McCosker in RCS promotional flyer for Patrick MacManaway's course, 2014.

2 Eliade used the word sacred to mean: beyond 'natural' realities; something that goes beyond the natural experience of humans; the opposite of the profane; the manifestation of something of a wholly different order, a reality that doesn't belong to our world, and can be in objects that are an integral part of our natural 'profane' world (Eliade, 1961: 10-11).
} 
it has a trans-human structure...not strictly confined to man's mode of being...' This is because, he says, 'in living, religious [i.e. spiritual] man is never alone, part of the world lives in him' as 'cosmic symbolism adds a new value to an object or action, without affecting their peculiar and immediate values'. Eliade concludes that

Openness to the world enables religious [spiritual] man to know himself in the world." This means that "the whole of life is capable of being sanctified ...thus life is lived on a two-fold plane; it takes its course as human existence and, at the same time, shares in a trans-human life, that of the cosmos or the gods.

Eliade (1961: 166-167)

Such an 'organic' mindset allowed people the capacity to listen to, feel strongly and empathically with, and identify the organic world around them, in all its manifestations. A crucial aspect of this was a sensitivity to 'subtle energies' (such as those emanating from flowing water or cosmic energy flows). In time, and in certain cultures, a very sophisticated series of practices - if you like a 'science' - was built up around detecting, concentrating and using these energies to good effect for human health, harmonious living and agricultural performance.

Is it any wonder, therefore, that while an extraordinary regenerative agriculture revolution unfolds across our nation and other countries and landscapes, such farmers and others who empathically reconnect to Mother Earth are now discovering, developing or unexpectedly encountering elements of the old organic mind? For this is what is surely occurring. I see it as part of the transformative shift to a third mind for this new era of human existence on Earth: the Emergent Mind. This mind combines elements of the old 'organic' (through an indivisible 'oneness' with the Earth and nature and a capacity to rediscover intuition, Earth-empathy and a mental freedom to be open to other outside and non-rational or spiritual influences) with the best of the modern 'mechanical' mind (such as research about our bio-geochemical world, ecological systems, and complex adaptive systems thinking and so on). The result is this new mind, the 'emergent', equipped with the best of the old and the new. It is thus capable of forging a new agriculture and a new urban-rural connection that regenerates, and doesn't destroy, the Earth.

In order to understand the potential of a new regeneration of agriculture, we need to at least open up and discuss some of the things that are emerging as modern regenerative farmers take steps that end up - intentionally or otherwise - connecting them to some long-lost or neglected ancient pathway.

\section{HARNESSING SUBTLE ENERGY THROUGH GEOMANCY}

In tracing the emergence of a regenerative agriculture and of the innovative farmers behind it, we see that the management approaches leading to ecological regeneration stem from a regeneration of degraded landscape functions. Such regeneration hinges on solar energy and the solar cycle and then flows into the soil-mineral, water and other cycles, and into that of dynamic ecosystem communities. Intersecting with, and indivisible from, these landscape functions is the human-social landscape element. But without solar energy, we humans would be immediately exterminated.

Nevertheless, there is another and complementary energy source that impacts the Earth and its organisms (including humans). Forgotten, over-looked or even repressed, this consists of the wider cosmic energy forces from further out in the solar system (including planetary and lunar influences) and beyond - from the broader galaxy. ${ }^{3}$ There are also energies generated from within the Earth, from processes relating to deep geological fault-lines to radioactivity. Though seemingly not as powerful nor obvious as solar energy, ancient people with an organic mindset recognised these additional energies and used them to maintain harmony with Earth's living patterns, for living and healing in general, particularly for agriculture, as well as for spiritual purposes.

${ }^{3}$ Much academic literature exists on cosmic rays and cosmic energies. See, for example, Dorman and Dorman, 2014. 
Such energies go under the general description of 'subtle energies'. It is no accident that modern regenerative farmers - in moving to a post-mechanical mindset - have discovered and recognised these and increasingly begun to use them to regenerative effect.

Subtle energies come in different forms and expressions, but quite simply, they are those energies present within and around us, which are beyond perceiving by our standard five senses. Moreover, conventional instrumentation can't measure these energy frequencies. However, importantly, they affect living systems at the cellular level, and this is dependent upon both the perception of the quality and character of the energy, and the sensitivity of living systems to the energy. In the modern scientific era, Albert Einstein first mooted some of these energies, which later led to the field of quantum physics: things too small to be seen but which are a basic part of our world, matter and the universe.

Our restricted modern worldview recognises just five main descriptions of subtle energies in our environment: electricity, magnetism, gravity, and weak and strong nuclear forces. Yet our living systems themselves are bio-electromagnetic (Malmivuo and Plonsey, 1995), and we can only see, hear and touch a narrow range of these frequencies. There is a good reason for our restricted perceptions: if we were able to perceive, feel, hear, etcetera everything out there, then we would be in a constant state of sensory overload.

The detection of magnetic energy lines and energy flows, patterns, auras or force fields is a skill that can be developed - as I found out in that park in Dubbo. In everyday language, such detection is called divining or dowsing, and in the case of treating animals or humans has various names, such as radionics and kinesiology. Ancient people with an organic mindset were incredibly sophisticated at detecting and experiencing subtle earth energies. That is why they attributed them to the activity of the Earth Spirit or nature spirits. The purpose of applying these skills was to connect themselves to special places, times, cosmic positions and to purpose. The age-old science of doing this is called 'geomancy'. ${ }^{4}$

Because their minds were totally trusting of their indivisibility with Mother Earth and her cosmic forces, such peoples were able to enter more directly into the spiritual realm: much of which is a realm of energy and mind and includes the physical power of human thought. This, as a researcher in the field, Nigel Pennick, says, led to people of an organic mindset revering 'stream and fountain, rock and grove, not as gods in themselves...but as inherent sources of the spirits of the earth such as the Yarthlings and Hyter Sprites, still talked of in East Anglian folklore' (Pennick 1979: 7-9).

Places of geographical interest were aligned on identified or dowsed energy lines called leylines. Sacred monuments and megalithic arrangements were erected on these lines at key nodal points, which were deemed to resonate with special psychic energy.

In short, there was an ancient geomantic and geophysical knowledge which underpinned most of the major religions of the world and which was largely lost as the organic mindset morphed into the rationalist, sceptical mechanical mind. This knowledge is now being put to constructive applied use by human healers, geomantic earth healers and regenerative farmers who in many other respects have moved into the post-mechanical or emergent mindset.

\section{THE ART OF DOWSING}

As I wandered around the city park in Dubbo, refining my dowsing skills, I reflected on how, over my life, I had met various water diviners or dowsers. A now deceased friend of the family, not far from our home, had an English aunt who used to come out to walk his farm and, through water divining, would accurately map his underground streams. During World War II, this lady was called in by the Ministry of Defence to divine the whereabouts of German U-boats. She used a pendulum over a map to do so. ${ }^{5}$

\footnotetext{
4 "Geomancy: or "earth divination", is the subtle relation between humans and their natural surroundings. It is the science of putting human habitats and activities into harmony with the visible and invisible world around us' (Pennick, 1980: 7).

${ }^{5}$ In the UK in 2017, 10 out of the 12 main private water companies were using dowsing to locate water (Le Page, 2017).
} 
But now I know people of all sorts and persuasions who, in an unencumbered way, have developed or discovered dowsing skills. Key to all these examples is people putting their 'mind' to the task. This word 'mind' is the secret because, as I soon discovered at Dubbo, successful dowsing is all about a concentrated focus of the human mind - or the use of what is termed mental 'intent'.

Mental thought is a basic physiological manifestation - that is, a concentrated stream, focussing and use of physical energy. As such, this different form of 'energy' focus may have physical and chemical effects across distance and even time. In spiritual matters, this is a component of prayer. The physical and/or chemical manifestation of the directed focus of human intention has also been written about as 'psycho-energetics' (Krippner, 1979), a term developed by Czech physicist František Kahuda (1911-1987). ${ }^{6}$ Similar concepts have also been expounded by Lipton (2011). One example is the remarkable quantified and photographed effects of Japanese scientist Dr. Masaru Emoto who, through powerful concentrated positive thought and even music, has shown that it is possible to change the shape of water molecules and crystalline structures (Radin et al., 2006).

From a farmer's perspective, a healthy water cycle is a key landscape function, and we all know water is the lifeblood of the living (especially in my dry continent of Australia). People like Patrick MacManaway hold water in the highest esteem. 'It is the consciousness of the earth, planet and soils', he said in his course. 'It is the matrix that holds the quality of consciousness, and beautiful, patterned, bright water crystals are vital for human and landscape health'. Water can be divined not just because its movement creates an electromagnetic force but also because even deep water underground has an energetic effect on the surface. Moreover, other subtle energies in or below our landscapes can also be divined.

So at Dubbo, I learnt to detect various underground streams by focussing clearly on finding water. When found, my divining rods suddenly and vigorously swung inwards and crossed on my chest. My divining also included finding a major health energy point where streams intersected. It is no accident that such nodes were ancient sacred sites or the location of temples and then churches. But once found, and again through mental focus and use of a binary 'yes/no' series of questions, I could then determine the approximate depth of the water below the surface. Experienced diviners/ dowsers and experts in subtle energy can do this with considerable accuracy.

Patrick MacManaway makes an important distinction between 'dowsing' and other 'divinatory approaches'. Dowsing (or the art of divining for something that is desired), as I learnt with wire rods, is straightforward. You clear your mind and focus thought 'intent' and use a simple and specific binary approach of 'yes' or 'no'. Such dowsing is not new. Moses divined water in the desert with a rod over 3,500 years ago, and indeed evidence of dowsing dates back to at least 8,000 years (Webster, 2008).

All sorts of dowsing tools can be used, but predominantly bent wire rods or wooden forked sticks and wands. A few people dowse with their hands, and some use a simple pendulum: usually a small piece of pottery, wood, plastic, metal or a piece of jewellery. One calibrates the tool by determining the response to 'yes' or 'no' via the way the pendulum moves, and then proceeds to ask a series of binary questions. Such questions, as I found among leading regenerative farmers, can apply to any field of activity.

In that Dubbo park, I then switched from water and focussed on detecting positive energy flows in the landscape and I was also able to find these, and in different places to the underground water streams. Again, it was because I had focussed my mental 'intent'. However, there are also negative energies that can cause illnesses, sleeplessness and such. Geopathic stress is caused by detrimental energy zones that can arise from underground sources. These can be due to geological faults and fractures, or from water flowing through such fault-line cracks in the underlying rock

\footnotetext{
${ }^{6}$ The term psycho-energetics also features in a draft proposal published by the CIA to investigate psycho-energetic phenomena, which defines this term as 'remote viewing/extra sensory perception' (ESP), or psychokinesis. Draft Proposal: DoD Psychoenergetics Program. Released 2008/08/08. https://www.cia.gov/library/readingroom/docs/CIA-RDP9600789R002100230001-3.pdf.
} 
strata. This field has been scientifically studied since the 1920s, particularly in Germany, under the rubric of geo-biology, and more recently has been researched in various other locations (see, e.g., Dharmadhikari et al., 2010; Freshwater, 1997; Hacker et al., 2005; Klimentov et al., 2015; Saunders, 2003; Wojtkun, 2017). Part of Patrick MacManaway's work is to diagnose such 'geopathic stress' and to heal or deflect the negative and pathological flows, through earth acupuncture or other mechanisms.

The ancient tradition of using earth acupuncture to address such negative subtle energies goes back to Neolithic and early Egyptian and Greek times (Comerford, 2012; Keen, 2018). MacManaway uses copper rods to deflect or divert the negative energies, which he finds resolves problematic situations for humans, animals and agricultural crops. That is why Terry McCosker calls this use of subtle energies 'the next big "freebie" in agriculture'. According to them, farms that have employed these methods have seen improvements such as increased crop production, conversion of standard bulk wheat grades to higher 'prime-hard' Australian Standard Wheat (ASW) grades, reduced pest and disease incidence in crops and animals, increased germination levels, more uniform growth, increased pollination levels, improved quality of produce (such as in nutrient levels and consequently taste), in energy or plant sugars (as measured by Brix levels), and of course underlying these changes, improvements in soil health and water quality.

\section{FIELD TOWERS AND BROADCASTERS}

The other device that is increasingly used by regenerative farmers is an adaptation of another ancient tradition. During World War II, biophysics scientist Dr Philip Callahan ${ }^{7}$ found himself stationed in Ireland as a radio technician, where he came across round towers dating back to the ninth century (of which there is a network of $~ 50$ ). After studying these in combination with his specialist knowledge of insect sensilla (receptors which gather information about the environment), Callahan postulated that they 'were constructed at ancient Christian monasteries where the Celtic monks practiced a form of eco-agriculture dependent upon crop and pastoral animal rotation' (Callahan, 1984: 26).

Callahan had described and measured the two magnetic forces of paramagnetism and diamagnetism, and he saw that monks could have used these towers - that were constructed of paramagnetic stone - to focus, collect and concentrate cosmic and earth paramagnetic energies, which then radiated (antennae-like) from the tower base to 'dope' their cropping soils and fields with a subtle energy that increased the paramagnetic properties of the surrounding soil and fields. This, he concluded, stimulated growth, health and well-being in plants, animals and thus humans (Callahan, 1995). ${ }^{8}$ Callahan went on to call these ancient monks 'the forefathers of good, modern, biological farming'. To recreate on a small scale the equivalent of the monk's giant magnetic antennae used for concentrating paramagnetic energy, Callahan's work inspired regenerative farmers to build smaller versions of these towers that are now being used around the world to generate good 'growth forces'.

As I drove around Australia, visiting regenerative farmers who have made the mind-shift to a post-mechanical mindset, I encountered a wide variety of these 'power towers', the first of which were constructed in the late 1980s. Most of these farmers would, a few years previously, have ridiculed such 'way-out', 'new-ageist' devices which they would most likely associate with some pot-smoking group of hippies. Today, one can see a plethora of tower designs, ranging from sculpture-like layered terracotta pipes, to PVC pipes of varying diameters and heights. When properly dowsed and sited, one can see visible, wave-like energy radiating from the top of the pipes - similar to the waves of energy that reflect off hot surfaces in summer (Moore, 2001: 166).

\footnotetext{
${ }^{7}$ Dr Philip Callahan (1924-2017), entomologist, ornithologist, explorer, photographer and philosopher, whose research involved the utilisation of non-linear far infrared radiation by biological systems and its applications to insect control and medicine. His work in biophysics focussed on insect molecular bioelectronics.

${ }^{8}$ There is little research so far on the relationship between paramagnetic properties and horticulture or agriculture (though, see Teixeira da Silva and Dobránszki, 2016), although rock dust is used as a soil amendment (Anon, 2012).
} 
Farm-emitters or broadcasters are a more sophisticated version of power towers. They are sited and built on the same principles, but with the added purpose of transmitting, for example, biodynamic preparations and other mixtures or ingredients, sometimes over hundreds, even thousands of acres. Such towers involve a strong degree of mental 'intent' or concentrated positive mental energy, so their users usually place a map of the desired area of influence and even a written statement of intent in the tower along with the biodynamic preps or other substances.

Interestingly, through the use of mental 'intent', many dowsers can map-dowse with a pendulum. Time and again, I have seen cases where the location of towers, over the confluence of underground streams or leylines, was first marked on a map in the homestead kitchen, or even hundreds of kilometres away in an office. When the physical dowsing was done in situ, the map-dowsed locations were accurate to within metres.

As Dr Phillip Callahan summarised the issue: because the majority of American (and Australian) farmers 'no longer farm according to the laws of nature (eco-agriculture), but rather according to the quick fix - whereby we have become drug the soil addicts' (Callahan, 1984: 117). But, 'no amount of nitrogen, phosphorous and potassium can replace the rock-generated paramagnetic force that is eroded from our soils by the sheer stupidity of our modern agricultural practices' (ibid). Conversely, if we work with nature, 'then insects and disease problems will take care of themselves. Healthy plants, properly nourished, will fight off attacks from outside, the same way healthy people do' (ibid).

\section{INDIGENOUS TOTEMS AND NATURE SPIRITS}

On my drive back from Dubbo Park, my mind was so full of ideas and information that the trip seemed like 5 minutes. Everything 'old' seemed 'new' again, I reflected and then remembered another incident when I was sitting around a campfire with local Aboriginal Ngarigo Elder, Rod Mason. We were near my home, up on a thickly timbered hill with giant granite boulders, where there had once been a major Aboriginal camp. In the course of a long conversation, in which I felt I was back in kindergarten, Rod (who is a highly respected man) told me that in his early training, he was taught how to use and integrate both brain hemispheres.

I wondered then whether this physiological development had been part of the cognitive-symbolic evolutionary step that had differentiated us from all other creatures, yet had been somewhat lost since the Age of Enlightenment.

Elders of the Wolgal-Bemmerangal clan of our local Aboriginal Ngarigo people are 'water people': rainmakers. According to Rod Mason, the spirits of the Wolgal-Bemmerangal return first to the water and not the sky, as is the case with members of other clans. As a consequence, Rod's people have a particular responsibility for water, as well as for animals and for their management.

The central grassland and woodland area of the Monaro where I live comprises a broad tableland - the 'big grass country' or Narrawallee. Our Narrawallee country (today recognised as a rich, highly mineralised and paramagnetic country) was also called the 'healing grounds' by the Ngarigo people. In springtime, they would dally there on their way to the ceremonial country in the mountains and the Bogong moth feasts and once again on their return home in the autumn.

Rod Mason told me that there are many spirits alive across our big grass and granite boulder country. These can be ancestors' spirits or nature spirits. The Ngarigo believe that the extraordinarily varied and beautiful boulders on our land are Elders who have passed on. They keep watch over the land and must be respected: the bigger the boulder, the more powerful the spirit. In every landscape, there is one very large and special rock - the Gurrubung: the caretaker rock. This contains a powerful spirit watching over the land, and people often go to sit at its base to seek comfort and imbibe spiritual benefits.

A kilometre from our house, and its sacred kurrajong tree, we have our own Gurrubung: two conjoined giant granite rocks we call 'bull rock', because (intriguingly, in retrospect) a bull died there decades ago. Its bones are still there and both our children and grandchildren have played 
with them. These two rocks are $80 \mathrm{~m}$ long and $15 \mathrm{~m}$ high and have been weathered over hundreds of millions of years. Partly submerged in the soil, they curve like a pair of giant blue whales breaching, replete with deep eye-sockets and blowholes. It is perhaps no coincidence that a pair of regal wedge-tail eagles nest in a large ribbon-gum tree overlooking this Gurrubung.

There are other spirits out in the grasslands: nature spirits such as the Mirrakarbalee, the ancient bird people. Children around campfires are told of these bird people, with their long, curved beaks and strange legs, who dwell in Narrawallee ready to pounce on and steal any child who wanders off alone.

Central to this story is that most Australian indigenous people (who are animists) have evolved a worldview called 'totemism', in which they form what seems to 'Westerners' to be mystical associations with plants, animals, natural features or phenomena, and even created objects. This runs parallel with uni-lineally related human groups (such as lineages, clans and tribes). A person's totem can thus determine their name or group and can involve totemistic symbols and emblems, taboos and prohibitions applied to their totem animal, plant and such. This connects them with a large number of animals and natural objects. Again, living in the spiritual world is the basis of their animistic existence and their close association with, and indivisibility from, nature.

The depth and complexity of the Australian Aboriginal worldview and its longevity in sustaining and managing Australia's varied ecosystems are due to evolved, interconnected and diverse features such as The Dreaming, The Law or Tjukurpa, Dreaming Tracks, Songlines, and their associated kinship arrangements that are linked to totems. All these are enmeshed in reinforcing Aboriginal myth, story, song, dance and art.

This Aboriginal knowledge and its associated beliefs organised the management and nurturance of 'country'. In a brilliant speech at the National Library in 2013, historian and scholar Bill Gammage pointed out that the knowledge that guided Australian Aboriginals' sustainable and regenerative management of 'country' was gained both physically and mentally over millennia, but also was a fusion with the spiritual in the land - with the religious. He said that the extraordinary indigenous knowledge and understanding of country - this "mighty intellectual achievement...a fusion of ecology and religions' (Gammage, 2013: 2) - was because the Dreaming

Is grounded on ecological realities, whatever its social applications. It taught why the world must be maintained; the land taught how. One made land care compulsory, the other made it rewarding. One was spiritual and universal, the other practical and local. In their country, people lived the World of the Dreaming, thronged with plants, animals and elements, each in their appointed localities. Not only obvious features which Europeans named, but every pebble and ripple disclosed both the ecological logic of its existence and the Dreaming's presence.

Gammage (2013)

'Dreaming site and ecological niche alike proved the need and reward in caring for country' continued Gammage. He further explained that

Totems expressed this. In English 'totem' can mean just a badge, for Aboriginals it is a life force stemming from and part of a creator ancestor - the soul a person shares with that ancestor's plant or animal and its places and ceremonies. An emu man does not have emu as a mere badge: he is emu, of the same soul and the same flesh. He is of its totem, not the reverse, and he must care for emu and its habitat, and they must care for him. A man "born along the track of the wallaby" might say, when seeing a wallaby, "that is me, that wallaby, that is me", or "that is my father".

\section{Quote from a 1984 manuscript "Nintirringu" in Bradley (2001) $)^{9}$}

We modern Westerners may scoff at the idea of nature spirits and people's ability to communicate with and, even, encounter them. We may even dismiss indigenous people as primitive, superstitious

${ }_{9}^{9}$ M de Graaf, 'Nintirringu', ms 1984; John Bradley 11 July 2001, cited by Gammage, 2013. 
or over-imaginative, but to them, the spirit world is real. The key point is that indigenous people have not lost connection to Mother Earth and Nature. They are truly organic in as much as they see themselves as a small, indivisible part of her. This leaves them open to experiencing and recognising natural energies, features and entities that the modern Western mind has become totally blind to.

In some respects, nature spirits are a manifestation of subtle energies in our landscape that we, modern, mechanically minded humans have lost the art of detecting. So it didn't come as a surprise to me when Patrick MacManaway, on that subtle energy course in Dubbo, quite naturally began to discuss the issue of nature spirits. This came about when he began to explain the various forms and uses of subtle energy.

According to Patrick, not only does this nature spirit world exist, but it is different in different lands and landscapes. Fairy tales are instructive on how to treat nature spirits; in Scotland, the Fairy Queen Sidhe, who lives in a sacred mountain, is the boss of nature. People maintaining the surviving Celtic worldview still see nature sprites and faeries, as real and active, and elsewhere in Europe, there are elves, gnomes, trolls, wights, pixies, gremlins, gronkydoodles and such that live in and around rocks, forests, streams, glades and other places. Today, in Norway, for example, there are still troll-catchers and stories abound of trolls' visible presence. Ancient people respected these nature spirits and worked with, or placated, them.

However, Australia is different to Europe and its diverse cultures. After 60,000-plus years of Australian nature - and spirit - empathic indigenous land management and living, it was inevitable that the establishment of the first incomers' settlement in 1788 would lead to a violent clash of cultures or hemispheres. A modern Western approach characterised by being rational, cruel, and exploitative and destructive of the land was imposed virtually overnight. As a result, the ancient human custodians of the land and their connection to a nature spirit reality suffered displacement and widespread destruction. In the process, a sacred human-earth bond was broken and displaced by a destructive, dominating, agriculture which the land had never seen before.

Patrick taught us that the connection to a nature spirit reality needs to be rebuilt and that the elemental spirits are still available. He explained, 'a landscape that doesn't yet recognise agriculture cannot help it'. We can learn from ancient medieval farmers in the UK and Europe who once communicated with nature spirits and the Earth, once showered them in blessings and, in turn, received their support. The clear implication is that, first of all, we need to work empathically with the landscape to regenerate it by harmoniously and lovingly using its functions. Then, we can work with the various nature spirits to free up the different earth, soil and other natural energies and elemental associated spirits.

On the long drive home, I had much time to ponder over our three packed and mind-bending days of lectures, discussion, dowsing and other energetic practices and found myself recalling a line from Fritjof Capra in The Web of Life: 'Ultimately, deep ecological awareness is spiritual or religious awareness' (Capra, 1997: 7)

\section{REFERENCES}

Anon (2012) Volcanic soil improver goes on sale at B\&Q. Horticulture Week, June 22, p. 15.

Bradley, J. (2001) Landscapes of the mind, landscapes of the spirit: Negotiating a sentient landscape. In R. Baker, J. Davies and E. Young (eds), Working on Country: Contemporary Indigenous Management of Australia's Lands and Coastal Regions, pp. 2295-2307. Oxford: Oxford University Press.

Callahan, P.S. (1984) Ancient Mysteries, Modern Visions: The Magnetic Life of Agriculture. Metairie, LA: Acres USA, 148 p.

Callahan, P.S. (1995) Paramagnetism: Rediscovering Nature's Secret Force of Growth. Metairie, LA: Acres USA, $128 \mathrm{p}$.

Capra, F. (1997) The Web of Life: A New Synthesis of Mind and Matter. New York: Harper Collins.

Comerford, K. (2012) Newgrange and the New Science: Exploring the Subtle Energies of Ireland's Ancient Neolithic Monuments. Dublin: CTM Books.

Dharmadhikari, N., Rao, A., Pimplikar, S., Kharat, A., Aghav, S., Meshram, D., Kulkarni, S. and Jain, B. (2010) Effect of geopathic stress on human heart rate and blood pressure. Indian Journal of Science and Technology, 3(1): 54 . 
Dorman, L.I. and Dorman, I.V. (2014) Cosmic Ray History: Space Science, Exploration and Policies Series. New York: Nova Publishers.

Eliade, M. (1961) The Sacred and the Profane: The Nature of Religion. New York: Harper Torchbooks.

Freshwater, D. (1997) Geopathic stress. Complementary Therapies in Nursing and Midwifery, 3(6): 160-116. Gammage,W.(2013)ThebiggestestateonEarth. Writing the AustralianLandscape Conference, 3-4 August 2013. Canberra: National Library of Australia. https://www.nla.gov.au/content/the-biggest-estate-on-earth.

Hacker, G.W., Pawlak, E., Pauser, G., Tichy, G., Jell, H., Posch, G., Kraibacher, G., Aigner, A. and Hutter, J. (2005) Biomedical evidence of influence of geopathic zones on the human body: Scientifically traceable effects and ways of harmonization. Forschende Komplementärmedizin und klassische Naturheilkunde. Karger, 12: 315-327.

Keen, G. (2018) The Mind's Interaction with the Laws of Physics and Cosmology. Newcastle-upon-Tyne: Cambridge Scholars Publishing.

Klimentov, V.V., Prohorov, G.V., Gozhenko, S.A. and Zukow, W. (2015) New aspects of solving the problem indication and measurements and geopathogenic anomalous zones. Journal of Education, Health and Sport, 5(4): 109-116.

Krippner, S. (1979) Psychoenergetic Systems: The Interaction of Consciousness, Energy, and Matter. London: Gordon \& Breach Science Publishing (Taylor \& Francis Group).

Le Page, S. (2017) In 2017, UK water companies still rely on "magic". November 20, 2017. Medium online news platform. https://medium.com/@sallylepage/in-2017-uk-water-companies-still-rely-on-magic6eb62e036b02 (accessed October 13th 2020)

Lipton, B. (2011) The Biology of Belief: Unleashing the Power of Consciousness, Matter and Miracles. London: Hay House.

Malmivuo, J. and Plonsey, R. (1995) Bioelectromagnetism: Principles and Applications of Bioelectric and Biomagnetic Fields. Oxford: Oxford University Press.

Moore, A. (2001) Stone Age Farming: Eco-Agriculture for the 21st Century. Castlemaine: Python Press.

NAILSMA (2006) Indigenous ecological knowledge: A Northern Territory scoping study. Prepared by the North Australian Indigenous Land and Sea Management Alliance (NAILSMA) for the Natural Resource Management Board, Northern Territory, April 2006.

Pennick, N. (1979) The Ancient Science of Geomancy: Man in Harmony with the Earth. London: Thames \& Hudson.

Pennick, N. (1980) Sacred Geometry: Symbolism and Purpose in Religious Structures. Wellingborough: Turnstone Press.

Radin, D., Hayssen, G., Emoto, M. and Kizu, T. (2006) Double-blind test of the effects of distant intention on water crystal formation. Explore, 2(5): 408-411.

Saunders, T. (2003) Health hazards and electromagnetic fields. Complementary Therapies in Nursing and Midwifery, 9(4): 191-197.

Taylor, B. (ed) (2005). Encyclopedia of Religion and Nature. London/New York: Continuum.

Teixeira da Silva, J. and Dobránszki, J. (2016) Magnetic fields: How is plant growth and development impacted? Protoplasma, 253(2): 231-248.

Webster, R. (2008) Dowsing for Beginners. Woodbury, MN: Llewellyn Publications.

Wojtkun, G. (2017) Human residential environment and radiesthesia. Surveying Geology \& Mining Ecology Management (SGEM) International Multidisciplinary Scientific GeoConference: SGEM, 17: 469-475. 